\title{
Comparison of numerical, analytical, and empirical models to estimate wetting patterns for surface and subsurface drip irrigation
}

\author{
Maziar M. Kandelous · Jiří Šimůnek
}

Received: 30 June 2009/Accepted: 17 December 2009/Published online: 7 January 2010

(C) The Author(s) 2010. This article is published with open access at Springerlink.com

\begin{abstract}
Due to increasing competition for water resources by urban, industrial, and agricultural users, the proportion of agricultural water use is gradually decreasing. To maintain or increase agricultural production, new irrigation systems, such as surface or subsurface drip irrigation systems, will need to provide higher water use efficiency than those traditionally used. Several models have been developed to predict the dimensions of wetting patterns, which are important to design optimal drip irrigation system, using variables such as the emitter discharge, the volume of applied water, and the soil hydraulic properties. In this work, we evaluated the accuracy of several approaches used to estimate wetting zone dimensions by comparing their predictions with field and laboratory data, including the numerical HYDRUS-2D model, the analytical WetUp software, and selected empirical models. The soil hydraulic parameters for the HYDRUS2D simulations were estimated using either Rosetta for the laboratory experiments and inverse analysis for the field experiments. The mean absolute error (MAE) was used to compare the model predictions and observations of wetting zone dimensions. MAE for different experiments and directions varied from 0.87 to $10.43 \mathrm{~cm}$ for HYDRUS-2D,
\end{abstract}

Communicated by J. Ayars.

M. M. Kandelous · J. Šimůnek ( $ه)$

Department of Environmental Sciences,

University of California Riverside,

Riverside, CA 92521, USA

e-mail: jiri.simunek@ucr.edu

M. M. Kandelous

e-mail: mkandelous@gmail.com from 1 to $58.1 \mathrm{~cm}$ for WetUp, and from 1.34 to $12.24 \mathrm{~cm}$ for other empirical models.

\section{Introduction}

Surface and subsurface drip irrigation systems are one of the most efficient systems for irrigating crops, vegetables, and fruit trees. Optimally designed drip irrigation systems should produce water distribution between the emitters and laterals as uniformly as possible. Water distribution is strongly affected by the soil hydraulic properties, spacing and depth of emitters and laterals, and the emitters' discharge.

There are a number of models that describe infiltration from a point/line source that can be used to design, install, and manage drip irrigation systems (e.g., Camp 1998; Singh et al. 2006). Some of these analytical, numerical, and empirical models have been developed to estimate wetting zone dimensions for surface and subsurface drip irrigation from a point source. While empirical models have typically been developed using a regression analysis of field observations, analytical and numerical models usually solve governing flow equations for particular initial and boundary conditions. A different approach was suggested by Lazarovitch et al. (2007) who introduced a moment analysis approach to describe spatial and temporal subsurface wetting patterns for irrigation from surface/subsurface drip irrigation systems.

On the one hand, Cook et al. (2003) developed a userfriendly software tool that uses analytical solutions to estimate the wetting pattern for different soil hydraulic properties, emitter positions, and volumes of water applied to homogenous soils from a surface or subsurface point source. On the other hand, HYDRUS-2D (Šimůnek et al. 1999) is a well-known Windows-based computer software 
package that uses numerical techniques to simulate water, heat, and/or solute movement in two-dimensional, variably saturated porous media. This software has been evaluated by several researchers who assessed its ability to simulate water movement from the subsurface drip irrigation system (e.g., Śimůnek et al. 2008, and references given there). For example, Liga and Slack (2004) used HYDRUS-2D to estimate the wetting pattern for subsurface drip irrigation, but did not compare the results of HYDRUS-2D simulations with actual experimental data. Skaggs et al. (2004) carried out an extensive analysis of multiple subsurface drip irrigation field experiments, and successfully compared observed wetting patterns with HYDRUS-2D model predictions. Lazarovitch et al. (2005) implemented into HYDRUS-2D a new, system-dependent boundary condition that considers source properties, inlet pressure, and effects of the soil hydraulic properties on calculated subsurface source discharge and validated resulting code against transient experimental data. Cook et al. (2006) compared wetting patterns estimated for both surface and subsurface drip irrigation systems using WetUp and HYDRUS-2D. This study was purely theoretical and did not involve any observation data. Cook et al. (2006) found that similar results were provided for fine-textured soils by both models. Note that models based on analytical and numerical solutions of the governing flow equation do not necessarily provide the same results, since analytical models often involve many simplifying assumptions that may not fully represent the observed reality.

Several empirical models have been presented in the literature to estimate the distance of the wetting front from a surface or subsurface dripper. For example, Schwartzman and Zur (1986) developed an empirical model to estimate the vertical and horizontal distances of a wetting front from a surface point source. Their empirical model was developed based on experiments carried out in the field on two soils (Gilat loam and Sinai sand), with emitter discharges of $1.1 \times 10^{-6}$ and $5.6 \times 10^{-6} \mathrm{~m}^{3} \mathrm{~s}^{-1}$. Amin and Ekhmaj (2006) verified this model using several experimental datasets and modified it by including the saturated soil water content as one of the model parameters. Finally, Kandelous et al. (2008) developed an empirical model for estimating upward, downward, and horizontal distances from the wetting front to a subsurface point source. This empirical model was developed based on data collected in the laboratory on the clay loam soil using a subsurface dripper installed at a depth of $30 \mathrm{~cm}$ and having an emitter discharge of $2.78 \times 10^{-7} \mathrm{~m}^{3} \mathrm{~s}^{-1}$.

In this paper, we compare the accuracy of these different empirical, analytical, and numerical models for estimating dimensions of the wetting zone, compare their predictions against laboratory and field data, and discuss their particular advantages and disadvantages.

\section{Description of various models}

\section{Numerical model HYDRUS-2D}

Since all experiments used only one emitter as the point source of water, water movement during infiltration could be considered an axisymmetrical process. The following Richards equation is the governing equation for water flow in a homogenous and isotropic soil:

$\frac{\partial \theta}{\partial t}=\frac{1}{r} \frac{\partial}{\partial r}\left[r K(h) \frac{\partial h}{\partial r}\right]+\frac{\partial}{\partial z}\left[K(h) \frac{\partial h}{\partial z}+K(h)\right]$

where $\theta$ is the volumetric water content $\left(\mathrm{L}^{3} \mathrm{~L}^{-3}\right), h$ is the soil water pressure head (L), $t$ is time $(T), r$ is the radial space coordinate $(\mathrm{L}), z$ is the vertical space coordinate $(\mathrm{L})$, and $K$ is the hydraulic conductivity $\left(\mathrm{LT}^{-1}\right)$. The soil hydraulic properties were modeled using the van Genuchten-Mualem constitutive relationships (van Genuchten 1980) as follows:

$\theta(h)=\left\{\begin{array}{l}\theta_{r}+\frac{\theta_{s}-\theta_{r}}{\left(1+|\alpha h|^{n}\right)^{m}} \quad h<0 \\ \theta_{s} \quad h \geq 0\end{array}\right.$

$K(h)=K_{s} S_{e}^{l}\left[1-\left(1-S_{e}^{1 / m}\right)^{m}\right]^{2}$

where

$S_{e}=\frac{\theta-\theta_{r}}{\theta_{s}-\theta_{r}}, \quad m=1-1 / n$

where $\theta_{s}$ is the saturated water content $\left(\mathrm{L}^{3} \mathrm{~L}^{-3}\right), \theta_{r}$ is the residual water content $\left(\mathrm{L}^{3} \mathrm{~L}^{-3}\right), K_{s}$ is the saturated hydraulic conductivity $\left(\mathrm{LT}^{-1}\right)$, and $\alpha\left(\mathrm{L}^{-1}\right), n(-)$ and $l(-)$ are shape parameters.

HYDRUS-2D uses the Galerkin finite-element method to solve the governing water flow equation. For subsurface drip simulations, the transport domain, for which the numerical solution was obtained, was rectangular, except for the semicircle on the left side of the domain representing the dripper. The location of the semicircle depended on the location of the dripper. During water application, a constant flux boundary condition was used at the emitter. The constant water flux was calculated by dividing the water discharge by the surface area of the emitter. At the end of the irrigation event, the emitter boundary became a zero flux boundary (Skaggs et al. 2004). The remaining part of the left boundary was a zero flux boundary both during and after the irrigation event. Zero flux boundary conditions were used at the right and bottom boundaries, since the computational flow domain was large enough that these boundaries did not affect water flow in the domain. A zero flux boundary condition was also used at the soil surface because evaporation could be neglected due to the surface plastic mulch used during and 
after irrigation. For surface drip simulations, the transport domain was rectangular. All boundary conditions were zero flux, except a small part at the top of the domain close to the axis of symmetry that represented a surface dripper. The length of this part was such to prevent surface ponding during simulations. For all calculations, the standard version of HYDRUS-2D was used. No specialized dynamic boundary conditions suitable for various micro irrigation schemes (e.g., variable ponding for surface drip irrigation (Gärdenäs et al. 2005) or the effect of the back pressure for subsurface drip irrigation (Lazarovitch et al. 2005)) recently implemented into HYDRUS-2D were used.

\section{WetUp}

Cook et al. (2003) developed easy-to-use software that uses Philip's (1984) analytical solutions for flow from a surface or subsurface point to estimate a wetting perimeter for surface or subsurface drip irrigation. The distance between the emitter and the edge of the wetting front for a buried source is given implicitly by the following equation:

$$
\begin{aligned}
& T(R, \phi)=\frac{\exp \left(2 R \sin ^{2} \frac{1}{2} \phi\right)}{2 \cos ^{2} \frac{1}{2} \phi} \\
& \times\left\{\begin{array}{l}
R^{2}-R+\left[\ln \left(\cos \frac{1}{2} \phi\right)-R \sin ^{2} \frac{1}{2} \phi+\frac{1}{2}\right] \\
\ln \left(\frac{\exp \left[2 R \sin ^{2} \frac{1}{2} \phi\right]-\cos ^{2} \frac{1}{2} \phi}{\sin ^{2} \frac{1}{2} \phi}\right) \\
-\frac{1}{2}\left[L\left(\sec ^{2} \frac{1}{2} \phi \exp \left[2 R \sin ^{2} \frac{1}{2} \phi\right]\right)-L\left(\sec ^{2} \frac{1}{2} \phi\right)\right]
\end{array}\right\} \\
& 0<\phi<\pi
\end{aligned}
$$

where $r$ and $\phi$ are spherical polar coordinates (L), $R=\alpha_{w} r$ r 2 is the dimensionless length, $\alpha_{w}$ is the reciprocal of the macroscopic capillary length $\left(\mathrm{L}^{-1}\right)$, and $L(x)$ is the dilogarithm defined as:

$L(x)=-\int_{1}^{x} \frac{\ln x}{x-1} \mathrm{~d} x$

Dimensionless time $T$ in (4) is given by:

$T=\frac{\alpha_{w}^{3} Q t}{16 \pi \Delta \theta}$

where $Q$ is the discharge of the emitter $\left(\mathrm{L}^{3} \mathrm{~T}^{-1}\right)$ located at $(s, z)=(0,0), s$ is the radial distance and $z$ is the depth (L) ( $s=r \sin \phi, z=r \cos \phi), t$ is the actual time $(T)$, and $\Delta \theta$ is the average volumetric water content change behind the wetting front $\left(\mathrm{L}^{3} \mathrm{~L}^{-3}\right)$. Although WetUp is based on the analytical solutions described previously, it does not evaluate them in real time. WetUp contains a database of precalculated values for the predefined irrigation rates, application times, antecedent water contents, and emitter locations, and it only interpolates within this database once input parameters are specified by the user. The database in WetUp currently contains information for Australian soils reported by Clapp and Hornberger (1978) and Verburg et al. (2001), for emitter discharges varying from $1.40 \times 10^{-7}$ to $7.53 \times 10^{-7} \mathrm{~m}^{3} \mathrm{~s}^{-1}$, and for three different initial soil matric potentials of $-10,-6$, and $-3 \mathrm{~m}$; i.e., for dry, moist, and wet soils. The value of $\alpha_{w}$ given in the database for clay loam was used in calculations presented below.

For a surface source, the wetting perimeter is given by another equation as follows:

$$
\left.\begin{array}{l}
T(R, \phi)=\exp [R(1-\cos \phi)] \\
\times\left\{\begin{array}{l}
R^{2}\left(1-\frac{1}{2} \cos \phi\right)-R+ \\
\frac{1}{\cos \phi}\left[\begin{array}{l}
R(1-\cos \phi) \ln (1-\cos \phi) \\
+\ln \left(\frac{1-\cos \phi \exp [R(\cos \phi-1)]}{1-\cos \phi}\right) \\
-L(1-\cos \phi \exp [R(\cos \phi-1)])+L(1-\cos \phi)
\end{array}\right]
\end{array}\right\} \\
0<\phi<\frac{1}{2} \pi
\end{array}\right\}
$$

Since the wetting pattern calculated by WetUp is always elliptical, the diameters of the estimated ellipse were selected to represent dimensions of the wetting zone.

Schwartzman and Zur (1986)

Schwartzman and Zur (1986) developed an empirical model to estimate the wetting pattern from a surface point source. The empirical model was developed using experimental results for two soils (Gilat loam and Sinai sand) and for two emitter discharges $\left(1.1 \times 10^{-6}\right.$ and $\left.5.6 \times 10^{-6} \mathrm{~m}^{3} \mathrm{~s}^{-1}\right)$. The saturated hydraulic conductivities, $K_{s}$, were $2.4 \times 10^{-6} \mathrm{~m} \mathrm{~s}^{-1}$ for the Gilat loam and $2.4 \times 10^{-5} \mathrm{~m} \mathrm{~s}^{-1}$ for the Sinai sand. The Schwartzman and Zur (1986) empirical model is as follows:

$$
\begin{aligned}
& W=1.82\left(V_{w}\right)^{0.22}\left(\frac{K_{S}}{Q}\right)^{-0.017} \\
& Z=2.54\left(V_{w}\right)^{0.63}\left(\frac{K_{S}}{Q}\right)^{0.45}
\end{aligned}
$$

where $W$ and $Z$ are horizontal and vertical dimensions of the wetting profile in meters, respectively, $V_{w}$ is the total volume of applied water $\left(\mathrm{m}^{3}\right), Q$ is the emitter discharge $\left(\mathrm{m}^{3} \mathrm{~s}^{-1}\right)$, and $K_{s}$ is the soil saturated hydraulic conductivity $\left(\mathrm{ms}^{-1}\right)$. 
Amin and Ekhmaj (2006)

Amin and Ekhmaj (2006) developed the following equations for estimating horizontal $(R)$ and vertical downward $(Z)$ distances of the wetting front from the surface drip emitter using several different experimental datasets (Taghavi et al. 1984; Angelakis et al. 1993; Moncef et al. 2002; and $\mathrm{Li}$ et al. 2003) using nonlinear regression:

$R=0.2476 \Delta \theta^{-0.5626} V_{w}^{0.2686} Q^{-0.0028} K_{S}^{-0.0344}$

$Z=2.0336 \Delta \theta^{-0.383} V_{w}^{0.365} Q^{-0.101} K_{S}^{0.195}$

where $R$ and $Z$ are horizontal and vertical dimensions of the wetting pattern $(\mathrm{m})$, respectively, $\Delta \theta$ is the average volumetric water content change behind the wetting front, $V_{w}$ is the total volume of applied water $\left(\mathrm{m}^{3}\right), Q$ is the emitter discharge $\left(\mathrm{m}^{3} \mathrm{~s}^{-1}\right)$, and $K_{s}$ is the soil saturated hydraulic conductivity $\left(\mathrm{ms}^{-1}\right)$. It is often assumed, when no other guidance is available, that $\Delta \theta$ is equal to about half of the saturated soil water content (i.e., $\Delta \theta=\theta_{s} / 2$ ).

\section{Kandelous et al. (2008)}

Kandelous et al. (2008) developed the following equations for estimating horizontal $(W)$, vertical upward $\left(Z_{+}\right)$, and vertical downward $\left(Z_{-}\right)$distances $(m)$ of the wetting front from the subsurface emitter using dimensional analysis in a method similar to Singh et al. (2006):

$$
\begin{aligned}
& W=4.244 V_{w}^{0.526}\left(\frac{K_{S}}{Q Z}\right)^{(0.026)} \\
& Z_{+}=0.72 V_{w}^{0.344}\left(\frac{K_{S}}{Q Z}\right)^{(-0.156)} \\
& Z_{-}=0.66 V_{w}^{0.333}\left(\frac{K_{S}}{Q Z}\right)^{(-0.167)}
\end{aligned}
$$

where $V_{w}$ is the volume of applied infiltrating water $\left(\mathrm{m}^{3}\right), Q$ is the emitter discharge $\left(\mathrm{m}^{3} \mathrm{~s}^{-1}\right), K$ is the saturated hydraulic conductivity $\left(\mathrm{ms}^{-1}\right)$, and $Z$ is the emitter installation depth $(\mathrm{m})$. These equations were developed using experimental data from subsurface drip irrigation experiment with an initially air-dried clay loam and an emitter discharge of $2.78 \times 10^{-7} \mathrm{~m}^{3} \mathrm{~s}^{-1}$, during which the movement of the moisture front was monitored over time.

\section{Materials and methods}

The following two sections describe laboratory and field experiments that were carried out in collecting information about the wetting pattern for subsurface and surface drip irrigation.
Laboratory lysimeter experiments

Experiments were conducted at the central laboratory of the College of Agricultural and Natural Resources of the University of Tehran, Iran. Laboratory experiments were conducted on a $2 \mathrm{~m} \times 1 \mathrm{~m} \times 1.2 \mathrm{~m}$ lysimeter that had transparent walls and was filled with a clay loam soil (33.5\% clay, $39.7 \%$ silt, $26.8 \%$ sand) (Table 1 ). To prevent preferential flow along the walls, lysimeter walls were first treated with glue and sprayed with sand to create a course surface, before the soil was filled into the lysimeter.

A thin pipe connected a 2-cm-diameter sphere installed $30 \mathrm{~cm}$ below the soil surface with an emitter placed on the soil surface. Since the subsurface sphere, made of foamed plastic polymers to prevent clogging of the irrigation device, was directly hydraulically connected with the surface emitter, it represented in our physical model a subsurface dripper. The subsurface sphere was installed in the close vicinity and in the middle of one of the lysimeter walls. The lysimeter represented a half space of a subsurface drip irrigation problem and could thus be treated mathematically as an axisymmetrical problem. Water was delivered to the emitter using a $20-\mathrm{mm}$ nominal diameter polyethylene pipe from a reservoir located on a scale $3 \mathrm{~m}$ above the emitter. The average water discharge used in calculations was $3.6 \times 10^{-7}$ and $5 \times 10^{-7} \mathrm{~m}^{3} \mathrm{~s}^{-1}$ for the first and second irrigation experiment, respectively.

The shape of the wetting front was drawn on the transparent wall about every $2 \mathrm{~h}$ until the end of irrigation. ROSETTA (Schaap et al. 2001), a pedotransfer function software package that uses neural network models to predict soil hydraulic parameters from soil texture and related data, was used to estimate the soil hydraulic parameters $\theta_{r}$, $\theta_{s}, \alpha, n, K_{s}$, and $l$ for the van Genuchten-Mualem model. Parameters required for the most complex ROSETTA model are bulk density $\left(1.35 \mathrm{~g} \mathrm{~cm}^{-3}\right)$, percentages of sand (26.8\%), silt (39.7\%) and clay (33.5\%), and water contents for pressures of -33 and $-1,500 \mathrm{k} \mathrm{Pa}(0.25$ and 0.133 , respectively). For these input variables, ROSETTA predicted the following soil hydraulic parameters: $\theta_{r}=0.06 \mathrm{~m}^{3} \mathrm{~m}^{-3}, \quad \theta_{s}=0.41 \mathrm{~m}^{3} \mathrm{~m}^{-3}, \quad \alpha=2.3 \mathrm{~m}^{-1}$, $n=1.34, K_{s}=2.5 \times 10^{-6} \mathrm{~m} \mathrm{~s}^{-1}$, and $l=0.5$ (Table 2). The average initial volumetric water content obtained from measurements with soil sensors was $\theta_{i}=0.07 \mathrm{~cm}^{3} \mathrm{~cm}^{-3}$ for the first irrigation experiment and $0.11 \mathrm{~cm}^{3} \mathrm{~cm}^{-3}$ for the second.

Table 1 Soil physical properties

\begin{tabular}{lllll}
\hline & Clay (\%) & Silt (\%) & Sand (\%) & Bulk density $\left(\mathrm{g} \mathrm{cm}^{-3}\right)$ \\
\hline Lysimeter & 33.5 & 39.7 & 26.8 & 1.35 \\
Field & 32.5 & 36.5 & 31 & 1.55 \\
\hline
\end{tabular}


Table 2 van GenuchtenMualem's (van Genuchten 1980) soil hydraulic parameters

\begin{tabular}{lllllll}
\hline & $\theta_{r}\left(\mathrm{~cm}^{3} \mathrm{~cm}^{-3}\right)$ & $\theta_{s}\left(\mathrm{~cm}^{3} \mathrm{~cm}^{-3}\right)$ & $\alpha\left(\mathrm{m}^{-1}\right)$ & $n$ & $K_{s}\left(\mathrm{~m} \mathrm{~s}^{-1}\right)$ & $l$ \\
\hline Lysimeter & 0.06 & 0.41 & 2.3 & 1.34 & $2.5 \times 10^{-6}$ & 0.5 \\
Field & 0.07 & 0.38 & 1 & 1.89 & $5 \times 10^{-6}$ & 0.5 \\
\hline
\end{tabular}

\section{Field experiments}

Field experiments were carried out at the Research Field of the College of Agricultural and Natural Resources of the University of Tehran, Iran, on a clay loam soil (32.5\% clay, $36.5 \%$ silt, $31 \%$ sand) (Table 1). Twenty-five experiments included 15 surface drip irrigation experiments, 5 subsurface drip irrigation experiments with an emitter depth of $15 \mathrm{~cm}$, and 5 subsurface drip irrigation experiments with an emitter depth of $30 \mathrm{~cm}$. Each experiment was conducted in a different location of the same field and involved infiltration from a single emitter. Different irrigation volumes were used for different irrigation experiments. The emitter discharge in these experiments varied from $6.94 \times 10^{-7}$ to $7.14 \times 10^{-7}, 1.14 \times 10^{-6}$ to $1.3 \times 10^{-6}$, and $1.71 \times 10^{-6} \mathrm{~m}^{3} \mathrm{~s}^{-1}$ for the surface drip irrigation (denoted as experiments $\mathrm{A}, \mathrm{B}$, and $\mathrm{C}$, respectively), and from $5.28 \times 10^{-7}$ to $9.69 \times 10^{-7} \mathrm{~m}^{3} \mathrm{~s}^{-1}$ for subsurface drip irrigation. For each experiment, the same emitter discharge (the average emitter discharge during the experiment) was used in all models. Water from the reservoir was delivered with millimeter precision to the emitter using a 160-mm nominal diameter PVC pipe and a small pump (Fig. 1). At the end of each irrigation experiment, the soil around the emitter was dug out, and the distance of the wetting front from the emitter was measured in the horizontal, vertical downward, and vertical upward (in SDI experiments) directions. Maximum distances between the wetting front and the emitter in particular directions (upward, downward, and horizontal) were used in comparison with various models.

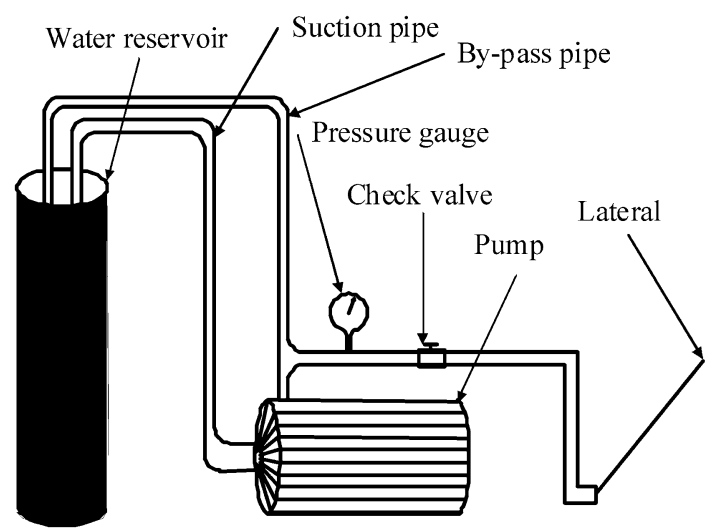

Fig. 1 A schematic of a pump and a water reservoir
Rosetta was used first to provide initial estimates of the soil hydraulic parameters from textural soil properties. However, HYDRUS simulations with the Rosetta-estimated parameters could not provide good descriptions of measured data. For example, the estimated saturated hydraulic conductivity $\left(5.0 \times 10^{-7} \mathrm{~ms}^{-1}\right)$ was too low to give good descriptions of moisture front movement. Note that Rosetta's estimates are based on soil textural properties and could thus describe reasonably well a repacked soil used in the laboratory, but did not work well for an undisturbed soil in the field where soil structure likely affected soil hydraulic properties. The soil hydraulic parameters for the field experiment were, therefore, further estimated using the inverse solution option of HYDRUS-2D and one additional subsurface drip irrigation experiment carried out specifically for this purpose. The emitter was installed $30 \mathrm{~cm}$ below the soil surface, and the average emitter discharge was $7.5 \times 10^{-7} \mathrm{~m}^{3} \mathrm{~s}^{-1}$ for $5 \mathrm{~h}$. At the end of the irrigation experiment, the soil surrounding the emitter was excavated to expose a vertical soil profile with the emitter in the center. Water contents measured at soil samples taken in three locations $(0,12.5$, and $25 \mathrm{~cm})$ away from the emitter and in four depths $(10,20,30$, and $40 \mathrm{~cm})$ were then used in the inverse analysis. Parameters $n$ and $K_{s}$ were optimized using HYDRUS-2D to get better description of the measured wetting pattern for this control experiment. The final estimated soil hydraulic parameters for a clay loam soil are $\theta_{r}=0.07 \mathrm{~cm}^{3} \mathrm{~cm}^{-3}, \theta_{r}=0.38 \mathrm{~cm}^{3} \mathrm{~cm}^{-3}$ (measured in the laboratory on soil samples), $\alpha=1 \mathrm{~m}^{-1}, n=1.89$, $K_{s}=5 \times 10^{-6} \mathrm{~m} \mathrm{~s}^{-1}$, and $l=0.5$ (Table 2). The average dry bulk density was $1.55 \mathrm{~g} \mathrm{~cm}^{-3}$. The average initial water content for the field experiments was $0.1 \mathrm{~cm}^{3} \mathrm{~cm}^{-3}$.

Statistical analysis

Mean absolute errors (MAE) between the simulated and measured dimensions of the wetting zone in different directions were calculated to provide a quantitative comparison between measured and simulated data.

$\mathrm{MAE}=\frac{1}{n} \sum_{i=1}^{n}\left|f_{i}-y_{i}\right|$

where $f_{i}$ and $y_{i}$ are observed and simulated values, respectively, and $n$ is the number of observations. All simulated and measured data were converted into the same units $(\mathrm{cm})$ before the MAE value was calculated for each model. 


\section{Result and discussions}

\section{Lysimeter experiments}

First, various model predictions are compared against two irrigation events carried out on the laboratory lysimeter. The numerical model, HYDRUS-2D, the analytical model, WetUp, and Kandelous' empirical model were used. Note that the other two empirical models discussed earlier are not suitable for subsurface irrigation, since they were developed for surface drip irrigation.

HYDRUS-2D and Kandelous' empirical model performed better than the WetUp for the first irrigation event (Fig. 2). As shown in Table 3, the value of MAE for different distances varied from 0.87 to $2.14 \mathrm{~cm}$ for HYDRUS2D, from 1.34 to $1.81 \mathrm{~cm}$ for the Kandelous' empirical model, and from 7.64 to $12.72 \mathrm{~cm}$ for WetUp. However, for the second irrigation event, WetUp performed better than the other models. Table 3 shows that values of MAE varied from 3.66 to $10.43 \mathrm{~cm}$ for HYDRUS-2D, from 1.45 to 11.9 for the Kandelous' empirical model, and from 3.79 to $5.25 \mathrm{~cm}$ for WetUp.

The soil profile was uniformly dry before the first irrigation event. In HYDRUS-2D simulations, the initial condition (given in terms of soil water content) was assumed to be uniform and equal to the measured soil water content.
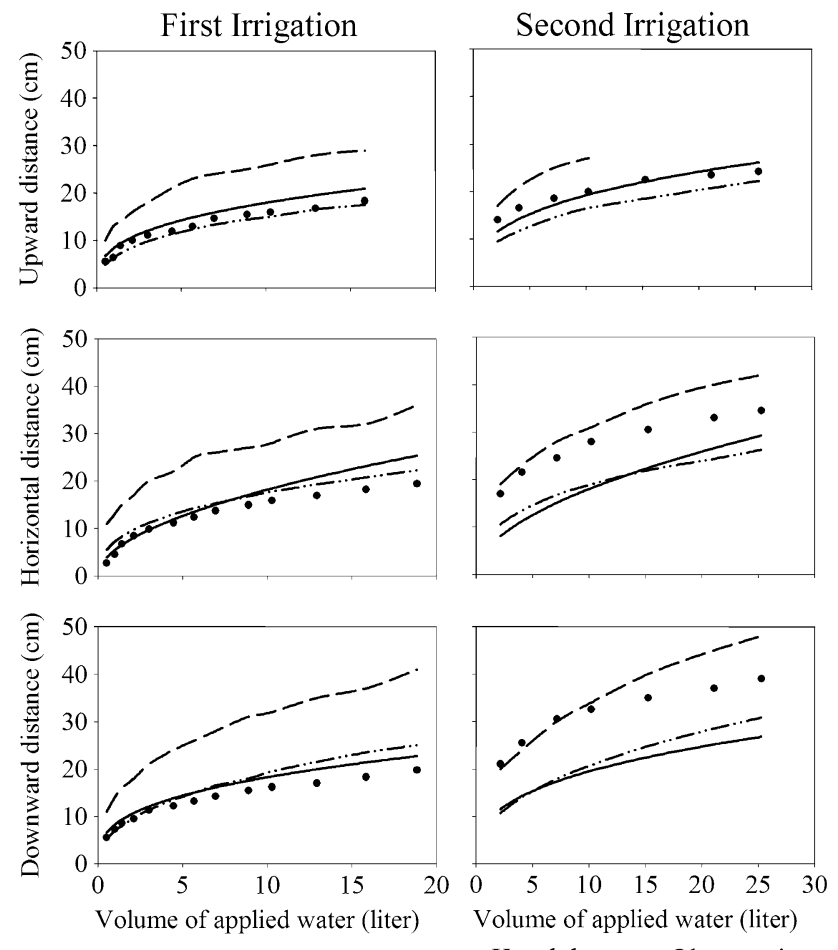

- - WetUp -.-. HYDRUS

Kandelous • Observation

Fig. 2 A comparison of observed and estimated wetting dimensions for the lysimeter experiments: the first irrigation experiment is on the left and the second irrigation experiment is on the right
Consequently, the model provided good predictions of the observed data when correct initial conditions were available. The Kandelous' empirical model, which was developed for a soil that is similar in dryness to the soil before the first irrigation, also provided good estimates. However, WetUp, which offers only three general initial conditions, i.e., dry (used here), moist, and wet, did not predict the dimensions of the wetting pattern well.

The second irrigation experiment (Fig. 2) was conducted two weeks after the first one when the initial soil water content was not uniform, but was still variable. However, although not required by the model, we still assumed that the initial condition was uniform and equal to the average soil water content for the entire soil profile in HYDRUS-2D calculations, in order to have the same conditions for all models. Because of this assumption, which did not fully correspond with reality, the accuracy of the HYDRUS-2D predictions decreased. The value of the MAE varied from 3.66 to $10.43 \mathrm{~cm}$ for HYDRUS-2D, from 3.79 to $5.25 \mathrm{~cm}$ for WetUp, and from 1.45 to $11.9 \mathrm{~cm}$ for the Kandelous' empirical model. The MAE values in Table 3 show that while WetUp performed better for the second irrigation event than the other models, it did not do so in predicting the upward movement. The empirical model of Kandelous, which was developed for different initial conditions (dry), could not provide good description of the wetting pattern.

At the beginning of irrigation, when water was infiltrating into the soil close to the emitter where the soil water content was higher than elsewhere, observed data and predictions by WetUp were closer to each other than at later times when the wetting front reached the drier soil. From this, it can be concluded that the soil water content around the emitter was similar to the soil water content used as an initial condition in WetUp (used with moist initial conditions here). Thus, once the wetting front reached the drier soil, differences between observed and estimated data started increasing. When about 10 liters of water was applied, WetUp estimated that the wetting front reached the soil surface and, therefore, the line in Fig. 2 stops. Again, it was assumed that the initial water content was equal to the average soil water content in the soil profile in the HYDRUS-2D simulation, which was less than the soil water content close to the emitter. Therefore, Fig. 2 shows that when the wetting front was close to the emitter, the observed front moved faster than the one predicted by HYDRUS-2D. The difference between observations and predictions decreased with the increasing distance of the wetting front from the emitter.

Field experiments

In this section, we will compare observed data and model predictions for both surface drip (DI) and subsurface drip 
Table 3 Statistical analysis for the comparison of observed and estimated data

\begin{tabular}{|c|c|c|c|c|c|c|c|c|}
\hline \multirow[t]{3}{*}{ Experiment } & \multirow[t]{3}{*}{ Experimental conditions } & \multirow[t]{3}{*}{ Models } & \multicolumn{6}{|c|}{ Wetting front dimensions } \\
\hline & & & \multicolumn{3}{|l|}{$R^{2}$} & \multicolumn{3}{|l|}{ MAE $(\mathrm{cm})$} \\
\hline & & & Horizontal & Upward & Downward & Horizontal & Upward & Downward \\
\hline \multirow[t]{6}{*}{ Lysimeter } & \multirow[t]{3}{*}{ SDI-30* First irrigation } & HYDRUS & 0.99 & 0.99 & 0.99 & 2.04 & 0.87 & 2.14 \\
\hline & & WetUp & 0.98 & 0.98 & 0.98 & 10.89 & 7.64 & 12.72 \\
\hline & & Kandelous & 0.98 & 0.98 & 0.98 & 1.34 & 1.74 & 1.81 \\
\hline & \multirow[t]{3}{*}{ SDI-30 Second irrigation } & HYDRUS & 0.99 & 0.98 & 0.96 & 8.2 & 3.66 & 10.43 \\
\hline & & WetUp & 0.98 & 0.98 & 0.96 & 4.29 & 5.25 & 3.79 \\
\hline & & Kandelous $^{\#}$ & 0.98 & 0.98 & 0.98 & 8.32 & 1.45 & 11.9 \\
\hline \multirow[t]{18}{*}{ Field } & \multirow[t]{3}{*}{ SDI-30 } & HYDRUS & 0.71 & 0.98 & 0.98 & 3.5 & 1.9 & 3.14 \\
\hline & & WetUp & 0.71 & 0.98 & 0.98 & 10.25 & 1 & 10.7 \\
\hline & & Kandelous & 0.72 & 0.96 & 0.98 & 2.2 & 8.95 & 5.93 \\
\hline & \multirow[t]{3}{*}{ SDI-15 } & HYDRUS & 0.94 & & 0.99 & 2.11 & & 4.34 \\
\hline & & WetUp & 0.86 & & 0.98 & 9.65 & & 5.6 \\
\hline & & Kandelous & 0.94 & & 0.98 & 1.83 & & 12.24 \\
\hline & \multirow[t]{4}{*}{$\mathrm{DI}_{-\mathrm{A}^{+}}$} & HYDRUS & 0.96 & & 0.89 & 3.05 & & 3.59 \\
\hline & & WetUp & 0.97 & & 0.90 & 55.43 & & 12.42 \\
\hline & & Schwartzman $^{\#}$ & 0.96 & & 0.84 & 5.3 & & 4.47 \\
\hline & & $\operatorname{Amin}^{\#}$ & 0.96 & & 0.86 & 1.96 & & 3.91 \\
\hline & \multirow[t]{4}{*}{ DI-B } & HYDRUS & 0.99 & & 0.93 & 2.43 & & 4.25 \\
\hline & & WetUp & 0.99 & & 0.92 & 58.1 & & 12.2 \\
\hline & & Schwartzman & 0.97 & & 0.95 & 4.59 & & 10.18 \\
\hline & & Amin & 0.98 & & 0.93 & 2.08 & & 4.01 \\
\hline & \multirow[t]{4}{*}{ DI-C } & HYDRUS & 0.98 & & 0.97 & 6.36 & & 9.76 \\
\hline & & WetUp & 0.96 & & 0.98 & 54.54 & & 21.5 \\
\hline & & Schwartzman & 0.98 & & 0.97 & 11.55 & & 4.42 \\
\hline & & Amin & 0.98 & & 0.97 & 8.14 & & 8.47 \\
\hline
\end{tabular}

* SDI-30 Subsurface drip irrigation with the emitter at a depth of $30 \mathrm{~cm}$

$+D I-A$ Surface drip irrigation. $A$ with discharge varying from $6.94 \times 10^{-7}$ to $7.14 \times 10^{-7} \mathrm{~m}^{3} \mathrm{~s}^{-1} ; B$ with discharge varying from $1.15 \times 10^{-6}$ to $1.3 \times 10^{-6} \mathrm{~m}^{3} \mathrm{~s}^{-1}$, and $C$ with the emitter discharge of $1.71 \times 10^{-6} \mathrm{~m}^{3} \mathrm{~s}^{-1}$

\# Kandelous, Schwartzman, and Amin refer to solutions given in Kandelous et al. (2008), Schwartzman and Zur (1986), and Amin and Ekhmaj (2006), respectively

(SDI) irrigations. While the numerical model HYDRUS2D and the analytical model WetUp are used for both surface and subsurface irrigation experiments, Kandelous' empirical model is used only for subsurface drip irrigation, and the empirical models of Schwartzman and Zur (1986) and Amin and Ekhmaj (2006) are used only for surface drip irrigation that is for conditions for which these particular empirical models were developed.

\section{Subsurface drip irrigation}

Subsurface drip irrigation experiments were conducted with emitters installed at a depth of 15 and $30 \mathrm{~cm}$ below the soil surface. A statistical comparison of observed data and those predicted by various models is presented in Table 3. No comparison was made for the upward direction for experiments with the emitter installed at a depth of $15 \mathrm{~cm}$, since all models predicted, as was also observed, that the wetting front would reach the soil surface during these experiments. The value of MAE varied from 2.11 to $4.34 \mathrm{~cm}$ for HYDRUS-2D, from 5.6 to $9.65 \mathrm{~cm}$ for WetUp, and from 1.83 to $12.24 \mathrm{~cm}$ for Kandelous' empirical model. In general, HYDRUS-2D provided better estimates than the other models. Although the initial soil profile was dry for all experiments, and thus was similar to the conditions, for which the Kandelous' empirical model was developed, the model did not provide good predictions for the downward direction.

Under natural (field) conditions, once the wetting front reaches the soil surface, downward water movement increases. Since empirical models, including the one by Kandelous, do not consider this phenomenon and estimate 
each direction (i.e., horizontal, upward, and downward) separately, observed downward water movement was much faster than predicted by the Kandelous' empirical model (Fig. 3).

Similar results were obtained for the infiltration experiments with the emitter installed at a depth of $30 \mathrm{~cm}$. HYDRUS-2D provided better estimates of wetting front movement than the other models. The MAE varied from 1.9 to $3.5 \mathrm{~cm}$ for HYDRUS-2D, from 1 to $10.7 \mathrm{~cm}$ for WetUp, and from 2.2 to $8.95 \mathrm{~cm}$ for the Kandelous' empirical model (Table 3).

\section{Surface drip irrigation}

Four models, i.e., HYDRUS-2D, WetUp, Schwartzman and Zur (1986), and Amin and Ekhmaj (2006) were used to analyze surface irrigation experiments (Fig. 4). Statistical comparisons between each model's predictions and observed data are presented again in Table 3 . The value of MAE varied from 2.43 to $9.76 \mathrm{~cm}$ for HYDRUS-2D, from 12.11 to $58.1 \mathrm{~cm}$ for WetUp, from 4.42 to $11.55 \mathrm{~cm}$ for Schwartzman and Zur's (1986) empirical model, and from 1.96 to $8.47 \mathrm{~cm}$ for Amin and Ekhmaj's (2006) empirical model. All models except WetUp provided good estimations of the wetting front. As shown in Fig. 4, WetUp overestimated the movement of the wetting front, while

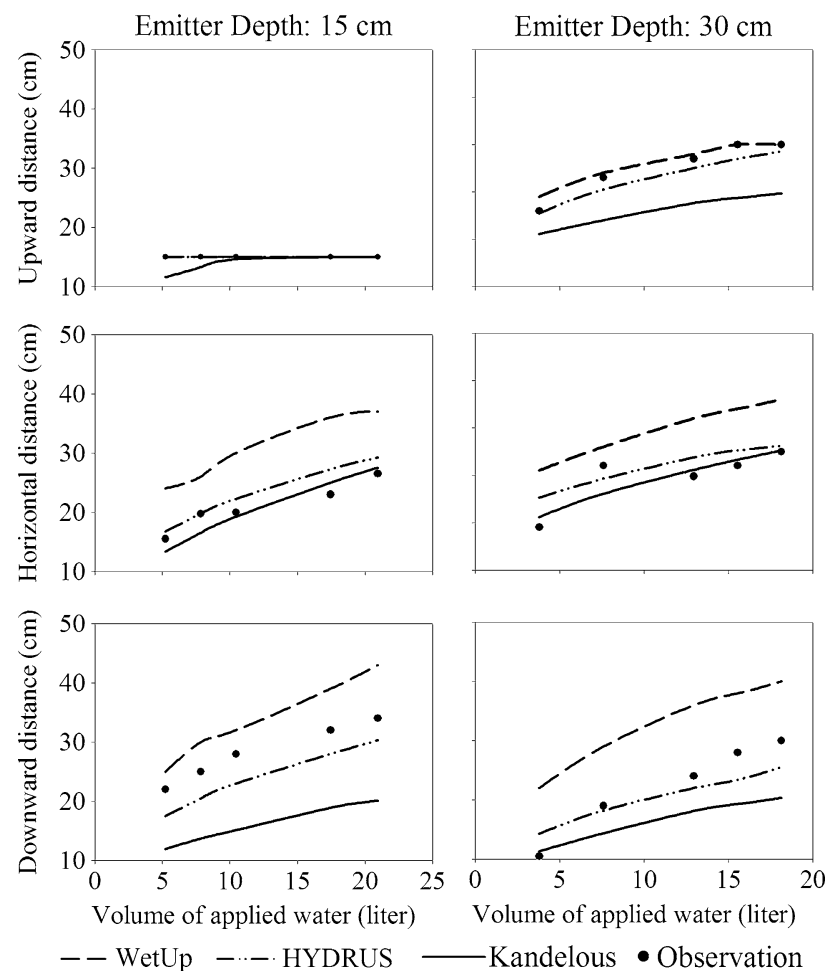

Fig. 3 A comparison of observed and estimated wetting dimensions for the field subsurface drip irrigation experiments with emitters installed at a depth of $15 \mathrm{~cm}$ (left) and $30 \mathrm{~cm}$ (right)
Schwartzman \& Zur's empirical model underestimated it. It can be concluded that HYDRUS-2D and the Amin \& Ekhmaj' (2006) empirical model provided better predictions than the other models because HYDRUS-2D uses soil hydraulic parameters that characterize the soil, and the Amin \& Ekhmaj' (2006) empirical model uses the $\Delta \theta$ variable.

It can be seen in Fig. 4 that for the experimental set C, which had the highest emitter discharge, HYDRUS-2D did not provide as good estimates as for the experimental sets $\mathrm{A}$ and $\mathrm{B}$. Ponding of water on the soil surface due to high emitter discharge could have caused the underestimation of the horizontal distance and the overestimation of the vertical distance. Water ponding at the soil surface would cause larger horizontal and smaller vertical movement of water when compared to conditions without ponding and for the same volume of irrigation water.

\section{Conclusions}

Wetting patterns for surface and subsurface drip irrigation were evaluated in this paper. While both laboratory and field experiments were conducted for the subsurface drip irrigation, only field experiments were carried out for the surface drip irrigation. Three models were used to estimate the wetting shape for the subsurface drip irrigation, but four models were used for the surface drip irrigation. A comparison of the model predictions against observed data was carried out and statistically analyzed.

HYDRUS-2D was used to represent numerical models simulating water flow and solute transport in soils and to estimate the wetting patterns for both surface and subsurface drip irrigation. The soil hydraulic parameters for the HYDRUS-2D simulations were estimated using either Rosetta for the laboratory experiments and inverse analysis of an additional control experiment for field conditions. Except for the second subsurface irrigation experiment in the laboratory and the experimental set $\mathrm{C}$ for the surface drip irrigation in the field, HYDRUS-2D estimations of the wetting shape were satisfactory, with values of MAE and $R$-square varying between 0.87 and $4.34 \mathrm{~cm}$ and 0.71 and 0.99 , respectively (Table 3). Although HYDRUS-2D is a rather complicated model that requires a lot of input data in order to simulate water movement in soils, this is balanced by more precise estimates of water movement from drip irrigation systems and the ability to use it for both surface and subsurface drip irrigation. It can be concluded that HYDRUS-2D provides good predictions and should be selected over other models evaluated in this paper when it is important to obtain accurate results.

Although the WetUp software is based on the analytical models for estimating the wetting pattern for surface and 
Fig. 4 A comparison of observed and estimated wetting dimensions for the field surface drip irrigation experiments. Experiments A (left) have a discharge varying from $6.94 \times 10^{-7}$ to

$7.14 \times 10^{-7} \mathrm{~m}^{3} \mathrm{~s}^{-1}$, experiments B (middle) from $1.14 \times 10^{-6}$ to

$1.3 \times 10^{-6} \mathrm{~m}^{3} \mathrm{~s}^{-1}$, and experiments $\mathrm{C}$ (right) have the emitter discharge of $1.71 \times 10^{-6} \mathrm{~m}^{3} \mathrm{~s}^{-1}$
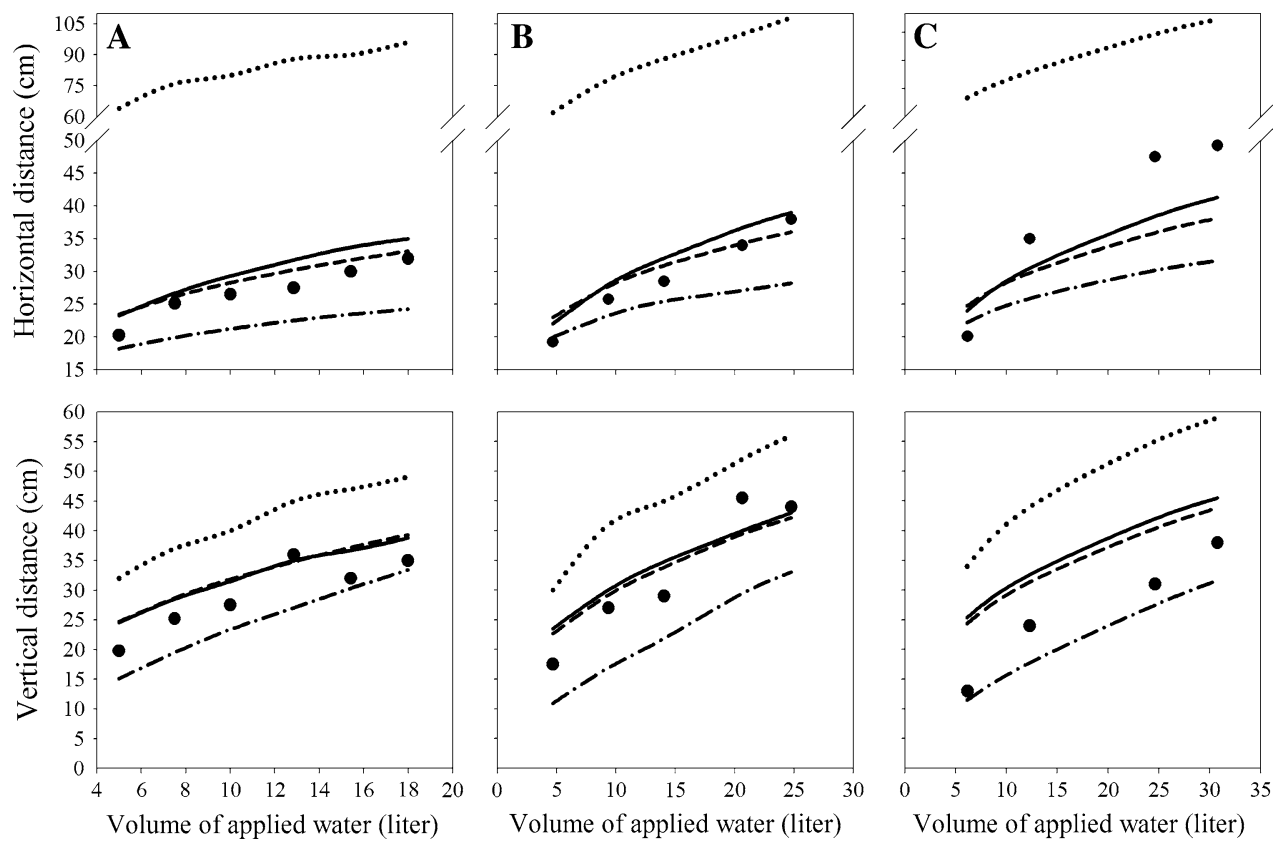

- Observed
Volume of applied water (liter)

HYDRUS

\section{WetUp}

----- Amin \& Ekhmaj (2006) -.-.-.- Schwartzman \& Zur (1984)

subsurface drip irrigation systems, its database is currently populated by values for selected Australian soils (that likely have a different type and structure than our soils) and conditions (Clapp and Hornberger 1978; Verburg et al. 2001). For soil types used in our experimental work and for considered initial conditions, WetUp was not a very useful tool. Its MAE and $R$-square values varied between 1 and $58.1 \mathrm{~cm}$ and 0.71 and 0.99 , respectively. While WetUp requires much fewer input parameters and shorter computational time to simulate wetting shapes than HYDRUS$2 \mathrm{D}$, its predictions are significantly less precise. WetUp would be a more useful tool if it evaluated analytical solutions directly for any entered parameters, in which case it could be used for a much wider range of soils and conditions.

The empirical model of Kandelous et al. (2008) for estimating the wetting shape for subsurface drip irrigation provided good results only for conditions that were similar to those for which it was developed. As shown in Table 1, values of MAE and $R$-square for the Kandelous' empirical model varied between 1.34 and $12.24 \mathrm{~cm}$ and from 0.72 to 0.98 , respectively. It can be concluded that this model is not general enough to be used for different conditions. The model needs to be further developed by considering different soil types, different initial soil water conditions, and perhaps other factors. An important defect of this model, similarly to WetUp, is that it cannot consider interactions between the water front and the soil surface once it is reached.

The empirical model of Amin and Ekhmaj (2006), which was developed to estimate the wetting pattern for surface drip irrigation, provided better results than the empirical model of Schwartzman and Zur (1986), and in some case even better than HYDRUS-2D. While MAE and $R$-square varied between 1.96 and $8.47 \mathrm{~cm}$ and from 0.86 to 0.98 , respectively, for Amin and Ekhmaj's empirical model of (2006), they were between 4.42 and $11.55 \mathrm{~cm}$ and from 0.84 to 0.98 , respectively, for the empirical model of Schwartzman and Zur (1986). The better predictive capabilities of the Amin and Ekhmaj (2006) model can likely be explained by its use of $\Delta \theta$, i.e., the average change of the soil water content behind the wetting front. It can thus be concluded that consideration of a parameter related to the soil water content is an important prerequisite for an empirical model to estimate wetting patterns for drip irrigation.

Open Access This article is distributed under the terms of the Creative Commons Attribution Noncommercial License which permits any noncommercial use, distribution, and reproduction in any medium, provided the original author(s) and source are credited.

\section{References}

Amin MSM, Ekhmaj AIM (2006) DIPAC-drip irrigation water distribution pattern calculator. In: 7th International micro irrigation congress, 10-16 Sept, PWTC, Kuala Lumpur, Malaysia

Angelakis AN, Rolston DE, Kadir TN, Scott VN (1993) Soil-water distribution under trickle source. J Irrig Drain Eng 119:484-500

Camp CR (1998) Subsurface drip irrigation: a review. Trans ASAE 41(5):1353-1367 
Clapp RB, Hornberger GM (1978) Empirical equations for some soil hydraulic properties. Water Resour Res 14:601-604

Cook FJ, Thorburn PJ, Fitch P, Bristow KL (2003) WetUp: a software tool to display approximate wetting pattern from drippers. Irrig Sci 22:129-134

Cook FJ, Thorburn PJ, Fitch P, Charlesworth PB, Bristow KL (2006) Modelling trickle irrigation: comparison of analytical and numerical models for estimation of wetting front position with time. Environ Model Softw 21:1353-1359

Gärdenäs A, Hopmans JW, Hanson BR, Šimůnek J (2005) Twodimensional modeling of nitrate leaching for various fertigation scenarios under micro-irrigation. Agric Water Manag 74:219 242

Kandelous MM, Liaghat A, Abbasi F (2008) Estimation of soil moisture pattern in subsurface drip irrigation using dimensional analysis method. J Agri Sci 39(2):371-378 (in Persian)

Lazarovitch N, Šimůnek J, Shani U (2005) System dependent boundary condition for water flow from subsurface source. Soil Sci Soc Am J 69(1):46-50

Lazarovitch N, Warrick AW, Furman A, Šimůnek J (2007) Subsurface water distribution from drip irrigation described by moment analyses. Vadose Zone J 6:116-123

Li J, Zhang J, Ren L (2003) Water and nitrogen distribution as affected by fertigation of ammonium nitrate from a point source. Irrig Sci 22(1):19-30

Liga M, Slack D (2004) A design model for subsurface drip irrigation in Arizona. Dep Agri Biosys, Arizona. Available online (http:// wsp.arizona.edu/sites/wsp.arizona.edu/files/uawater/documents/ Fellowship200304/liga.pdf). Checked on Dec 102009

Moncef H, Hedi D, Jelloul B, Mohamed M (2002) Approach for predicting the wetting front depth beneath a surface point source: theory and numerical aspect. Irrig and Drain 51:347-360
Philip JR (1984) Travel times from buried and surface infiltration point sources. Water Resour Res 20:990-994

Schaap MG, Leij FJ, van Genuchten MT (2001) ROSETTA: a computer program for estimating soil hydraulic properties with hierarchical pedotransfer functions. J Hydrol 251:163-176

Schwartzman M, Zur B (1986) Emitter spacing and geometry of wetted soil volume. J Irrig Drain Eng 112(3):242-253

Šimůnek J, Sejna M, van Genuchten MT (1999) The HYDRUS-2D software package for simulating two-dimensional movement of water, heat and multiple solutes in variably saturated media, Version 2.0. Rep. IGCWMC-TPS-53, p 251, Int. Ground Water Model. Cent., Colo. Sch. of Mines, Golden, CO

Šimůnek J, van Genuchten MT, Šejna M (2008) Development and applications of the HYDRUS and STANMOD software packages, and related codes. Vadose Zone J Vadose Zone Model 7(2):587-600

Singh DK, Rajput TBS, Singh DK, Sikarwar HS, Sahoo RN, Ahmad T (2006) Simulation of soil wetting pattern with subsurface drip irrigation from line source. Agri Water Manag 83:130-134

Skaggs TH, Trout TJ, Šimůnek J, Shouse PJ (2004) Comparison of HYDRUS-2D simulations of drip irrigation with experimental observations. J Irrig Drainage Eng 130(4):304-310

Taghavi SA, Marino MA, Rolston DE (1984) Infiltration from trickle irrigation source. J Irrig Drain Eng 110(4):331-341

van Genuchten MT (1980) A closed-form equation for predicting hydraulic conductivity of unsaturated soils. Soil Sci Soc Am J 44:892-898

Verburg K, Bridge BJ, Bristow KL, Keating BA (2001) Properties of selected soils in the Gooburrum-Moore Park area of Bundaberg. Technical Report 09/01, CSIRO Land and Water, Canberra, Australia 